\section{MESTRADO EM ENSINO DE CIÊNCIAS NATURAIS DA UNIVERSIDADE FEDERAL DE MATO GROSSO: A CONSOLIDAÇÃO DE UM PROGRAMA COMO CENTRO REGIONAL DE FORMAÇÃO DE PROFESSORES}

\author{
MASTER'S DEGREE IN NATURAL SCIENCES TEACHING AT THE \\ FEDERAL UNIVERSITY OF MATO GROSSO: THE CONSOLIDATION \\ OF A PROGRAM AS A REGIONAL TEACHER-TRAINING CENTER
}

Elane Chaveiro Soares ${ }^{1}$ Marcelo Paes de Barros²
1

Doutora em Educação (PUCRS-2012).

Coordenadora e orientadora no Programa de Pósgraduação em Ensino de Ciências Naturais/UFMT. Professora do Departamento de Química da UFMT elaneufmt@gmail.com. 2

Doutor em Física Ambiental (UFMT-2012). Orientador no Programa de Pósgraduação em Ensino de Ciências Naturais/UFMT. Professor do Instituto de Física da UFMT - marcelo. paes@fisica.ufmt.br
RESUMO: Apresentamos dados parciais de uma pesquisa de avaliação realizada pela coordenação do curso de Mestrado Profissional em Ensino de Ciências Naturais da Universidade Federal de Mato Grosso, junto aos seus egressos. Nesta etapa, foi enviado um questionário por e-mail contendo sete questões relacionadas ao curso e pós-defesa. Buscou-se informações sobre atuação profissional, a relação com a pesquisa, com a publicação, com o produto educacional desenvolvido, bem como os aprendizados na realização do curso. Neste texto, a discussão ocorreu em torno das três primeiras questões. Preliminarmente, conclui-se pela necessidade de aprofundamento epistemológico, bem como organização de espaços-tempos para o aprimoramento do produto educacional. Sua aplicação no âmbito da escola tem sido quase imediata e à continuidade da formação, pois os egressos estão seguindo para o doutorado.

palavras-chave: Mestrado Profissional. Produto Educacional. Formação contínua. Pesquisa em Ensino.

ABSTRACT: We present partial data of an evaluation research carried out by the coordination of the Professional Master's Course in Teaching of Natural Sciences of the Federal University of Mato Grosso, together with its graduates. In this stage, an e-mail questionnaire containing seven questions related to the course and post-defense was sent. Information was sought on professional activity, the relationship with the research, with the publication, with the educational product developed, as well as the learning in the accomplishment of the course. In this text, the discussion took place around the first three questions. Preliminarily, it concludes by the necessity of epistemological deepening, as well as organization of space-times for the improvement of the educational product. Its application within the scope of the school has been almost immediate and to the continuity of the formation, since the graduates are moving towards the doctorate.

KEY wORDS: Professional Master. Educational Product. Continuous formation. Research in Teaching. 


\section{INTRODUÇÃO}

A falta de professores habilitados no país provenientes da academia, especialmente na área de Ciências da Natureza, resultou no quadro atual, um elevado índice de professores não habilitados, estudantes e profissionais de outras áreas não relacionadas com as disciplinas regidas, buscando no Ensino a ocupação que não encontram em suas profissões de formação. Em Mato Grosso a carência de professores habilitados é ainda mais aguda quando restringimos o foco às disciplinas ofertadas para o Ensino Médio pelas escolas da Rede Pública. O problema se agrava quando este foco é lançado para as disciplinas das ciências da natureza.

Segundo dados do Censo Escolar, na Sinopse 2000, no Brasil existiam 1.115.761 professores sem formação em nível superior em todos os níveis de ensino. Em Mato Grosso, a realidade não é diferente. Na área de Ciências Naturais, foco deste Projeto, existiam, segundo levantamento da Secretaria de Educação do Estado de Mato Grosso (SEDUC/ MT) de 1997, 1618 professores sem graduação, 91\% de um quadro total de 1776 professores da área, nos mais diferentes municípios do Estado.

Diante desse quadro, para contribuir no sentido de valorizar o professor de Física, Química e Biologia, quer seja no aspecto de lhe instrumentalizar no que diz respeito a técnicas, instrumentos e teorias de ensino, quer seja na própria valorização salarial proporcionada pelo título de mestre, no ano de 2010 é oferecida, em Cuiabá, MT, a primeira turma do curso de Mestrado Profissional (MP) em Ensino de Ciências Naturais na Universidade Federal de Mato Grosso (UFMT).

O Programa de Pós-Graduação em Ensino de Ciências Naturais (PPGECN) foi constituído e catalisado através de projetos executados por um grupo de professores que se fundamentou na experiência em pesquisa e ensino, tanto no ensino fundamental, quando no médio e superior, responsabilizando-se pela consolidação das licenciaturas de cada linha na UFMT.

O primeiro projeto desenvolvido pelo grupo foi um programa interinstitucional, com a SEDUC/MT, no ano de 2003, com a implantação de um curso de Licenciatura Plena em Ciências Naturais e Matemática (LPCNM), modalidade presencial, no sistema modular, que qualificou duzentos professores de Ciências Naturais e Matemática, destes, cem habilitados em Matemática, cinquenta habilitados em Física e cinquenta em Química.

Além da SEDUC/MT, o programa vem contando com um expresso apoio institucional para sua consolidação - mesmo sendo um MP bem como, com fortes parcerias com instituições como a Universidade do Estado de Mato Grosso (UNEMAT) e o Instituto Federal de Mato Grosso (IFMT).

Voltado para a formação continua do professor, o PPGECN busca promover a atualização de um profissional que, tendo uma sólida formação nos conteúdos específicos da sua área, domine técnicas e 
instrumentos de ensino de Ciências Naturais nas condições reais de sala de aula, bem como de Teorias de Aprendizagem e Epistemologias, estabelecendo uma base sólida para as suas ações no contexto escolar.

Do ponto de vista institucional, o Programa promoveu, a partir de pesquisas sobre o aperfeiçoamento de técnicas e instrumentos de Ensino de Ciências em condições reais de sala de aula, o fortalecimento dos cursos de licenciaturas na área. A grande maioria dos ingressantes no programa são egressos das licenciaturas da UFMT.

Antes da criação deste Programa os egressos desses cursos que permaneciam na região, tinham poucas perspectivas de aprimoramento profissional em nível de pós-graduação stricto sensu.

Nesse contexto, o presente trabalho tem por objetivo apresentar os resultados do Programa nestes primeiros anos de existência, apontar ações viáveis de formação dentro do contexto atual da docência bem como instiga as possibilidades de continuidade da formação, dessa vez, almejando um Doutorado.

\section{O PROGRAMA DE PÓS-GRADUAÇÃo EM ENSINO DE CIÊNCIAS NATURAIS}

O currículo do PPGECN possui uma área de concentração, em Ciências Naturais na Educação Básica e superior, e conta atualmente com duas linhas de pesquisa: Formação de Professores para o Ensino de Ciências Naturais e Processos de Ensino e Aprendizagem em Educação Científica. As pesquisas desenvolvidas nestas linhas são abrangentes e integradas entre si na medida em que comportam os projetos atuais desenvolvidos no âmbito do Programa.

A proposta curricular do curso apresenta quatorze disciplinas cadastradas que buscam coerência com as linhas de pesquisa e a área de concentração. As disciplinas do eixo específico contemplam conteúdos disciplinares que corroboram à formação contínua do professor de educação básica, entendendo que as teorias orientadas para o conteúdo são um complemento necessário para plataformas teóricas como as abordagens construtivistas e socioculturais. As ementas e as referências bibliográficas de tópicos dessas disciplinas de conteúdos específicos, Tópicos de Física, de Química e de Biologia, são baseadas em obras clássicas, principalmente, e em artigos dos principais periódicos da área.

Através dessa proposta, que intenciona ser coerente, o curso visa qualificar o professor para uma inserção mais qualificada no pleno exercício da docência no campo das Ciências Naturais. Este, talvez, seja o maior desafio enfrentado na formação contínua para o exercício da docência que, conforme Fischer (2005), tem a necessidade de ser valorizado como experiência inovadora capaz de contribuir para a renovação da pós-graduação brasileira.

O Programa é composto por um corpo docente com larga experiência em ensino básico, superior e formação de professores. Doutores em Educação, em Ensino e nas áreas específicas, dos quais 4 são do- 
3

Informação disponível em http://www.mt.gov.br/ geografia, acesso 26 out 2017 centes titulares da UFMT, categoria mais elevada da carreira docente universitária no Brasil, que conta com apenas 40 representantes na instituição. Acreditamos que isso tem se refletido na baixa taxa de evasão de alunos e no desenvolvimento de materiais didáticos que atendem as necessidades do ensino de Ciências, por isso amplamente utilizados em salas de aula dos ensinos superior e básico.

É claro que a baixa evasão do programa não é comum. No nosso caso, o baixo índice tem outras variáveis como, o apoio do governo do Estado de Mato Grosso, que concede afastamento parcial e a cooperação da gestão escolar, que reorganiza a dinâmica da distribuição dos horários com a intenção de favorecer o mestrando.

Dados iniciais, apontam que o Programa, embora pequeno em termos numéricos, jovem e distante dos grandes centros de pesquisa e de formação, conta com um corpo docente experiente e comprometido e que já está em processo de consolidação e crescimento, desenvolvendo pesquisas e ações conectadas ao ensino e à extensão que vão de encontro às necessidades formativas dos professores da região.

\section{A INSERÇÃO REGIONAL DO PPGECN/UFMT}

O Estado de Mato Grosso - sede do programa - possui 903.357,908 $\mathrm{km} 2$ de extensão sendo o terceiro maior estado do país, ficando atrás somente do Amazonas e do Pará. Sua área urbana é de 519,7 km2, o que o coloca em $11^{0}$ lugar no ranking de estados com maior mancha urbana. Com a presença do cerrado, do Pantanal e como porta de entrada para a Amazônia 3 t, o estado apresenta-se com características utilitárias diversificadas e passiveis de aplicação nos projetos conduzidos pelos mestrandos e seus orientadores.

Percebe-se uma boa inserção dos projetos no interior do Estado - apesar das distâncias - o que vem gradativamente contribuindo para uma perspectiva de longo prazo da manutenção das linhas de pesquisa e do desenvolvimento e aprimoramento dos produtos educacionais.

Sua aproximação com a escola básica tem se dado basicamente por dois caminhos: a) pela atração de professores da rede estadual de ensino pela oferta frequente do curso e por meio de convênio com a SEDUC/MT (oferta de turma especial com ingresso em 2013 e conclusão em 2016), por meio do qual, os egressos têm produzido produtos educacionais que estão sendo aplicados diretamente em sala de aula por eles ou seus pares; b) pela oferta de projetos de extensão para aplicação direta na rede estadual de ensino, nos quais os mestrandos realizam atividades com alunos e/ou professores (como o realizado juntamente com a Semana de Minicursos das Práticas de Ensino de Química (SEMIPEQ) e o Projeto Canoa/Física).

Dos ingressantes, $87 \%$ são professores em pleno exercício da profissão e, desses, $85 \%$ pertencem à rede pública de ensino. Tal constatação reforça a consolidação do Programa como centro regional de formação de professores e de difusão de produtos, técnicas e projetos de pesquisa sobre o Ensino de Ciências Naturais nas condições reais 
das salas de aula espalhadas pelo Estado de Mato Grosso.

Até novembro de 2017, o curso titulou 72 professores como mestres em Ensino de Ciências Naturais. As dissertações e seus respectivos produtos educacionais, podem ser visualizados pelo endereço http:// fisica.ufmt.br/pgecn/.

O curso vem suprindo uma demanda significativa no âmbito da formação/atualização de professores que ensinam Ciências (Química, Física, Biologia) o que pode ser percebido pelo número de inscritos nos processos seletivos desde o seu início (Tabela 1):

TABELA 1 -Número de inscritos nos processos seletivos do PPGECN

\begin{tabular}{l|c}
\hline 2010.1 & 20 \\
\hline 2011.1 & 28 \\
\hline 2012.1 & 37 \\
\hline 2013.1 & 31 \\
\hline 2013.2 & $25^{*}$ \\
\hline 2014.1 & 31 \\
\hline 2015.1 & 60 \\
\hline 2016.1 & 40 \\
\hline 2017.1 & 40 \\
\hline 2018.1 & 38 \\
\hline
\end{tabular}

* Turma Especial-Convênio com a Secretaria Estadual de Educação do Estado de Mato Grosso (SEDUC/MT).

38 (Trinta e oito) concorrentes se inscreveram para o processo seletivo de 2018, que ofereceu 13 vagas - sendo 3 para o Ensino de Física, 3 para o Ensino de Biologia e 7 para o Ensino de Química - esta última, aumentada pelo credenciamento de mais dois doutores com formação na área.

Na última avaliação quadrienal, o programa logrou a nota 4,0 configurando uma atmosfera de boas expectativas para a coordenação, o corpo docente e discente, bem como para a instituição.

Para o quadriênio 2017/2020 a previsão é que haja a inserção de professores com formação Matemática, ampliando as vagas para ingresso e potencializando a articulação entre as áreas. Projetamos a evolução do programa para o oferecimento de vagas no âmbito do ensino de Matemática, com a inserção desta área nas linhas de pesquisa já existentes.

Neste texto, apresentamos dados parciais de uma pesquisa de avaliação realizada pela atual coordenação do curso junto aos egressos. Em fase de intensa revisão, o currículo do programa está passando por transformações que visam aprimorar e fortalecer os pontos positivos, bem como atacar as fragilidades e fomentar as possibilidades de melhoria. Como fora mencionado, intenciona-se a inclusão do Ensino de Matemática para o próximo processo seletivo (2019) e ressalta-se com isso, a visão de um salto, tanto qualitativo quanto quantitativo no oferecimento de novas perspectivas para o programa em um futuro próximo. 
Acredita-se que o egresso do curso pode fornecer indicações valiosas de como o investimento em sua qualificação impactou sua atuação e seu desenvolvimento profissional, tendo em vista, uma política brasileira de desmonte da educação básica e que delega cada vez menos subsídios à atuação do profissional docente em sua carreira.

\section{A PESQUisa}

A pesquisa foi aplicada aos egressos do Programa na forma de um questionário enviado ao endereço eletrônico destes, disponível no banco de dados do PPGECN. Os egressos responderam a sete questões relacionadas ao curso, durante no seu desenvolvimento e na vida profissional pós-defesa. Cada um dos egressos que respondeu à pesquisa foi identificado por uma letra e um número que se relaciona à sua área de atuação e à ordem de chegada do questionário ao e-mail da coordenação, da seguinte forma: Q1, Q2, Q3 ... B1, B2, B3 ... F1, F2, F3 .. para Química, Biologia e Física, respectivamente.

No questionário buscou-se informações sobre a atuação profissional, a relação com a pesquisa, com a publicação, com o produto educacional desenvolvido, bem como os aprendizados na realização do curso. A pesquisa permitiu ainda, atualizar os dados no sistema do programa, bem como traçar a trajetória de cada um em relação à pós-graduação, destacando a relevância do curso na formação, na consolidação e no desenvolvimento no campo de atuação.

A análise será concentrada na discussão em torno das três primeiras questões respondidas:

1. O que mudou em sua atuação profissional com a conclusão do Mestrado?

2. Está realizando ou planeja realizar outra formação (Doutorado ou outro curso)?

3. Já aplicou seu produto educacional pós-defesa e o atualizou?

Como a pesquisa é de cunho informativo, na perspectiva de observação e acompanhamento do desempenho dos egressos após a defesa e ao longo de sua trajetória profissional, com vistas a se compreender o impacto do mestrado, o questionário será recebido pela coordenação do curso de forma longitudinal. Registros e interpretações parciais serão feitos na medida em que novos dados forem catalogados. Dessa forma, elencamos aqui a análise das respostas de 17 (dezessete) egressos que enviaram o questionário respondido até o dia 5 de novembro de 2017. 


\section{DISCUSSÕES}

\subsection{A ATUAÇÃO PROFISSIONAL DOCENTE APÓS A REALIZAÇÃO DE UMA PÓS-GRADUAÇÃO}

É interessante observar que a inserção em um programa de pós-graduação está normalmente conectada às condições intelectuais, profissionais, financeiras e estruturais do interessado. Quatro variáveis que deveriam manter um tom equilibrado, levando-se em conta as necessidades formativas da carreira docente. No entanto, realizar um mestrado parece estar, muitas vezes, vinculado à ideia de ganho salarial ou de ascensão profissional, o que significa, muito provavelmente, que a perspectiva inicial não é a da realização de um aprofundamento teórico ou metodológico através da pesquisa. A constatação pode ser comum a muitos cursos semelhantes do país, segundo Schäfer e Ostermann (2013a), a partir de um estudo do curso de MP em ensino de Física da UFRGS, concluíram que a maioria dos professores egressos migraram para o Ensino Superior (privado, em geral) ou para os Institutos Federais de Educação, Ciência e Tecnologia (IFET), não permanecendo na escola em que lecionava ao ingressar no curso

Como em diversas regiões do Brasil, a demanda por professores formados em sua área de atuação no interior do Estado de Mato Grosso é alta. Consequentemente, a titulação os coloca em situação privilegiada de concorrência. No entanto, a grande maioria permaneceu em seus locais de trabalho. A análise das respostas dadas à primeira questão, demonstram que a fixação no local de trabalho é uma realidade para os egressos. Este dado é surpreendente e ao mesmo tempo explicável. Mesmo que vá na contramão do senso comum de dizer que, uma vez titulado, o professor não permanece na mesma escola, os egressos do PPGECN, pelo contrário, sim permanecem. No entanto, deve-se também destacar que o Estado não possui ainda uma oferta significativa de vagas para o ensino superior. Isso, somado nos últimos anos à exigência do título de doutor para que se possa realizar concursos federais pode também, explicar a permanência dos egressos nas escolas de origem.

Entre os dezessete (17) egressos que participaram da pesquisa, treze (13) continuaram atuando no mesmo nível e no mesmo local de trabalho em que estavam antes do início do curso, dos quais: dez (10) no Ensino médio da rede pública (B1, F2, F4, F5, F6, F7, F8, Q3, Q4, Q5); dois (2) no Ensino superior (F1 na UNEMAT e Q2 no IFMT) e um (1) no Centro de Formação e atualização de professores (CEFAPRO/MT) (Q6).

Por outro lado, essa fixação pode também, ter resposta na carência de profissionais habilitados nas Ciências Naturais em Mato Grosso, de forma que alguns desses egressos atualmente estão nas coordenações e direções, na Coordenação de Cursos de Graduação, condução de projetos de pesquisa e extensão, nesses mesmos estabelecimentos de ensino.

As alterações de nível foram detectadas, direcionando os egressos para uma atuação ou formação continuada mais aprimorada. Dois 
(2) começaram a atuar no ensino superior (B2 foi para a UNEMAT e $\mathrm{F}_{3}$ para o IFMT); Dois (2) foram para a SEDUC (B3 e Q1). Q4, que concluiu o MP em 2015, iniciou o Doutorado em Ciência dos Materiais pelo PPGCM do Departamento de Física e Química da UNESP em 2017.

Com relação ao desejado aprofundamento teórico ou metodológico através da pesquisa, em outro texto (sOAREs, 2016), quando tivemos a oportunidade de vislumbrar uma panorâmica dos trabalhos de pesquisa a nível de mestrado realizados na UFMT, destacamos que os consideráveis avanços obtidos pelas pesquisas feitas até então - tanto no profissional quanto no acadêmico e mais especificamente no ensino de Química - apontavam para uma necessária reformulação da prática docente, bem como para políticas públicas que valorizem mais a atuação em sala de aula. Sem estas políticas, todo o trabalho desenvolvido pela/na universidade esgota-se pela possibilidade de o egresso não continuar sua formação por falta de incentivo.

B1 destaca o seu envolvimento com as questões educacionais e de autoaprendizagem, bem como do relacionamento entre os pares:

"Penso que mudou em alguns aspectos principalmente em leituras, publicações, participações em eventos e na parceria com outros profissionais da educação. Acredito que a minha participação enquanto profissional também teve ganhos qualitativos e conquistou confiança de outros colegas".

Alguns egressos registram os convites para compor comissões e destacam a compensação salarial como contrapartida da titulação:

“Eu já era concursada no IFMT, continuo trabalhando como professora, contudo, depois do mestrado além da compensação salarial, fui convidada a elaborar o PPC do curso de Licenciatura em Química que está em processo de implantação no campus". (Q2).

Para Lage, Urzetta e Cunha (2011), as tendências atuais da formação continuada apontam para a necessidade de medidas políticas que potencializem a formação continuada, passando a incluir, na jornada de trabalho, tempo para: a docência (aulas), atividades pedagógicas (reuniões, planejamento) e para atividades de formação contínua, coletivas e em serviço na própria escola e, também, fora dela.

A virtude da formação continuada a partir da realização de um mestrado reside justamente no aprofundamento teórico e metodológico das ações, tanto acadêmicas, quanto profissionais. No caso do PPGECN, a instabilidade positiva provocada pela formação, enquanto em serviço, vem potencializando a inovação porque traz para a academia o dia-a-dia da sala de aula na perspectiva da pesquisa, forçando-os a fazer uma releitura do cotidiano docente. O que de forma alguma, quer dizer estagnação, como veremos nas respostas à segunda questão. 


\subsection{A PERSPECTIVA DE CONTINUIDADE DA FORMAÇÃO - UM DOUTORADO PROFISSIONAL?}

Com relação a perspectiva de estudos mais avançados, apenas um egresso não destacou a possibilidade da realização de um Doutorado. A maioria (16), ou está planejando, ou já se inscreveu nos seletivos para 2018 ou já está cursando, como é o caso de $Q_{4}$ citado acima.

Dentre os que planejam a realização de um curso de Doutorado está o pensamento de que esta é uma consequência natural da formação realizada no mestrado. Q1, por exemplo, revela que:

"Estou estudando para provas de doutorado fora do estado de Mato Grosso, de acordo com a linha de pesquisa que pretendo trabalhar, que é no Ensino por investigação, formação continuada e desenvolvimento profissional docente". (Q1).

Essa percepção vai no mesmo sentido dos resultados encontrados por Nepomuceno e Costa (2012), em coleta de percepções de egressos e seus chefes na organização onde trabalham, sobre a influência de um programa de mestrado profissional no desempenho dos egressos, que perceberam, os participantes da pesquisa, um maior impacto do curso nos aspectos que versam sobre o "perfil de pesquisador" do pós-graduado e a "autoestima".

Dois egressos enfatizam o desejo de que o Doutorado possa também ser realizado nos moldes do MP, como ressalta F8 ao dizer que:

“.... Ter vivenciado o mestrado neste programa foi uma oportunidade única, tudo me encantou e possibilitou acreditar mais ainda em uma educação com qualidade. Ficaria imensamente feliz realizar o doutorado neste programa. Acredito que ele continuará crescendo e um dia ofertará tal formação".

$\mathrm{Na}$ mesma direção, $\mathrm{F}_{4}$ também relata que:

"Gostaria de dar continuidade no produto desenvolvido durante o curso, afim de verificar o potencial enquanto facilitador de ensino aprendizagem para pessoas com deficiências visuais e auditivas".

Junto com a vontade de cursar um doutorado, eles mencionam também as dificuldades para sua realização, como destaca B2 ao dizer que:

"O doutorado, passou a ser meu novo objetivo, mais o vejo distante, pois trabalhar, criar filhos e estudar[ ...] é um tanto utópico da minha parte. A resposta é sim, pretendo continuar estudando e possivelmente fazer o doutorado em educação, algo voltado a cyber cultura, inclusão digital, meios de atividades experimentais (aulas práticas), algo voltado ao ensino de Biologia...". 
Ainda em 2005, Silveira e Pinto (2005, p.38) já nos lembravam que "alguns temas discutidos no Congresso Nacional dos Pós-Graduandos sempre causam maior polêmica que outros, contudo, poucos debates têm sido tão acalorados quanto o relativo ao mestrado profissional (MP) ". Tal questão é mesmo perceptível, tanto no âmbito regional, quanto no nacional.

Para Rezende e Ostermann (2015), não há como generalizar e enquadrar todos os MPs em uma mesma categoria, diante da variedade de MPs no ensino de ciências, resultantes dos processos de recontextualização, de forma que, não desconsiderando a importância dos aspectos curriculares, mas dada a heterogeneidade gerada pelos processos de recontextualização, seria mais relevante trazer para discussão aspectos estruturais, comuns a todos os cursos de MP em ensino.

A portaria 389, de março de 2017, destacou a relevância social, científica e tecnológica dos processos de formação profissional avançado, bem como o necessário estreitamento das relações entre as universidades e o setor produtivo resolvendo instituir no âmbito da pós-graduação stricto sensu, a modalidade de mestrado e doutorado profissional.

Por ocasião do $5^{\circ}$ seminário Nacional da área de Ensino - PG CAPES realizado no período de 8 a 1o de novembro de 2017 em Brasília, os coordenadores dos mestrados e doutorados presentes foram informados de que a Capes havia recebido sete projetos de intenção ao Doutorado Profissional (DP) em ensino. As discussões, ainda que preliminares e um tanto efusivas, giraram em torno do que poderia ser considerado um produto educacional validado em um DP, sobre a pouca disponibilidade para do profissional para estudos teóricos ou sobre a real necessidade desse tipo de programa, uma vez que os doutorados acadêmicos estão consolidados e muitos já alcançaram os patamares de excelência com notas 6 e 7 .

Ofato é que a demanda para o DP em ensino existe. Principalmente se considerada a demanda para o próprio MP e o caminho tomado por alguns de seus egressos. Os projetos enviados à Capes para análise e avaliação - caso sejam aprovados - serão os responsáveis primários pela demarcação das fronteiras, diga-se talvez, diferenças, entre o doutorado acadêmico e o profissional, bem como sobre sua pertinência e sua configuração.

\subsection{O PRODUTO EDUCACIONAL: SUA ATUALIZAÇÃO E APLICAÇÃO NA PRÁTICA PEDAGÓGICA}

Na proposta inicial do curso de MP em Ensino de Física da UFRGS, criado em 2002 e que serviu de modelo para o PPGECN, é hegemônico "que o desenvolvimento de um produto educacional - como, por exemplo, programas de computador, textos didáticos para alunos, textos de apoio aos professores, vídeos, equipamentos, páginas na internet, pôsteres e experimentos - seria obrigatório como trabalho de conclusão do MP, caracterizando-se como a diferença essencial entre este e o MA" (REZENDE E OSTERMANN; 2015, p. 551). 
Mesmo com tamanha importância, acreditamos que os produtos criados nos MPs, alguns mais e outros menos, são ainda protótipos que careçam de aprofundamentos teóricos, conceituais e práticos. O que não o invalida, pois, as dinâmicas de criação e aplicação são guiadas pela metodologia da pesquisa, e devidamente qualificadas por uma banca de doutores. Ao contrário do que a crítica comum espalha, há pesquisa no MP.

Os egressos ( $\left.F_{1}, F_{2}, F_{3}, F 6, F 8, B_{2}, Q_{2}, Q_{3}, Q_{4}, Q_{5}, Q 6\right)$ afirmaram que aplicam seus produtos no ensino médio, o que é feito, geralmente nas próprias turmas onde são professores. B3 e Q1 utilizaram o produto em formações docentes no CEFAPRO/MT e Fı aplicou em aulas do ensino superior. $\mathrm{F}_{7}$ e $\mathrm{B}_{1}$ apresentaram seus produtos em eventos e $\mathrm{F}_{4}$ gostaria de dar continuidade ao seu desenvolvimento.

Estes dados nos remetem a duas possíveis discussões. Em primeiro lugar, seria possível uma discussão relacionada ao cotidiano escolar que se impõe àquele que volta integralmente para a sala de aula depois de dois anos de qualificação. No caso dos MPs, a maioria não consegue afastamento integral da sala de aula e lida com as dificuldades de conciliar estudos, aulas, seminários, eventos, publicações e a realização da pesquisa em si. Isso faz com que, ao retornar para a rotina, sua imersão no trabalho se configura como prioridade e a única oportunidade para aplicar o produto seja mesmo na própria escola.

Em segundo lugar, estes produtos educacionais precisam ser analisados do ponto de vista da inserção social, como meio de impactar a educação provocando modificações nos processos, nas rotinas, na compreensão das ciências e sumariamente na qualidade do que se produz no ensino.

Do ponto de vista epistemológico, tanto a criação quanto a aplicação dos produtos precisam estar alinhados, por exemplo, à problemática das visões deformadas da ciência e da tecnologia encontradas no cotidiano educacional desde as salas de aula, passando pelos livros textos, pelas informações veiculadas pela mídia e aparecendo até mesmo nos cursos de formação de novos professores (CACHAPUz et al., 2005). Como afirmam estes autores:

Sem uma discussão profunda sobre esses aspectos da construção das ciências e a tomada de consciência de que em todas as nossas aulas e/ou atividades educacionais nós transmitimos implicitamente uma determinada concepção de mundo e influenciamos assim a formação de nossos alunos não conseguiremos promover uma renovação da educação científica. (CACHAPUZ et al., 2015, p. 10)

Dessa forma, os produtos educacionais, como são chamados na maioria dos MPs são em primeira instância, um exercício vigoroso de melhoria da própria prática pedagógica. Os mestrandos se envolvem substancialmente com a renovação das teorias de ensino e aprendizagem, com a ressignificação de conceitos, com o desenvolvimento de metodologias mais críticas, com a aplicação de instrumentos de pes- 
quisa e com a validação desse produto, a ponto de, muitas vezes, tornar este produto, o carro chefe de outras inovações que passa a levar para a sala de aula após a finalização do mestrado.

Para Ostermann e Rezende (2009), além de contemplar a eficiência de um método de ensinar dado conteúdo, seria necessário investir em produtos educacionais que envolvessem a reflexão sobre o problema educacional vivido pelo professor em uma dada realidade escolar. Nesse sentido, a respeito dos Produtos desenvolvidos no âmbito PPGECN os egressos afirmam que:

Estou aplicando o produto educacional com meus estudantes do Ensino Médio, para tanto, fiz algumas adaptações no mesmo. O produto continua me instigando a buscar metodologias ou práticas pedagógicas que envolvam as diferentes áreas do conhecimento, pois a complexidade do mundo exige o compartilhamento de conhecimentos. Juntos conseguiremos resolver muito mais os problemas que permeiam nosso cotidiano. Também tive a oportunidade de participar de uma oficina sobre construção de luneta juntamente com um professor do Instituto Federal na Semana Nacional de Ciências e Tecnologia...(F8);

Dessa forma, os produtos educacionais, como são chamados na maioria dos MPs são em primeira instância, um exercício vigoroso de melhoria da própria prática pedagógica. Os mestrandos se envolvem substancialmente com a renovação das teorias de ensino e aprendizagem, com a ressignificação de conceitos, com o desenvolvimento de metodologias mais críticas, com a aplicação de instrumentos de pesquisa e com a validação desse produto, a ponto de, muitas vezes, tornar este produto, o carro chefe de outras inovações que passa a levar para a sala de aula após a finalização do mestrado.

Para Ostermann e Rezende (2009), além de contemplar a eficiência de um método de ensinar dado conteúdo, seria necessário investir em produtos educacionais que envolvessem a reflexão sobre o problema educacional vivido pelo professor em uma dada realidade escolar. Nesse sentido, a respeito dos Produtos desenvolvidos no âmbito PPGECN os egressos afirmam que:

Estou aplicando o produto educacional com meus estudantes do Ensino Médio, para tanto, fiz algumas adaptações no mesmo. O produto continua me instigando a buscar metodologias ou práticas pedagógicas que envolvam as diferentes áreas do conhecimento, pois a complexidade do mundo exige o compartilhamento de conhecimentos. Juntos conseguiremos resolver muito mais os problemas que permeiam nosso cotidiano. Também tive a oportunidade de participar de uma oficina sobre construção de luneta juntamente com um professor do Instituto Federal na Semana Nacional de Ciências e Tecnologia... (F8); 
4

Centro de Formação e Atualização dos Profissionais da Educação Básica da Secretaria de Educação do Estado de Mato Grosso

5

Sala do educador: Formação $\mathrm{da} /$ na unidade escolar que objetiva fortalecer a escola como lócus de formação continuada. Disponível http://www.seduc.mt.gov. br/Paginas/default.aspx. Acesso em: 19 nov. 2017.
"Venho aplicando em minhas aulas, sei de dois professores que já usaram práticas do produto. Estou buscando novos mecanismos para aperfeiçoá-lo, espero que em breve venho melhora-lo e dar outra roupagem ao manual" (B2);

$\mathrm{B}_{3}$ destaca que: "Nas formações que ministro, trago como estratégica de ensino de Botânica, o produto educacional desenvolvido por mim, possibilitando momentos de aprofundamento teórico e prático";

"Apliquei o produto educacional no decorrer de minhas aulas no ano de 2016 e a partir dele, organizei um plano de formação para professores do processo de seleção para ingresso do CEFAPRO ${ }^{4}$, da qual fui aprovada" (Q1 ao levar sua ideia e seu produto educacional para um seletivo do $\mathrm{CEFAPRO}^{1} \mathrm{v} /$ MT).

Sim. O roteiro da peça: "Ombros de Gigantes", disponível em: file:///C:/Users/Administrador/Downloads/ Produto_H\%C3\%Agrcules.pdf, que não foi o meu primeiro trabalho que, de alguma forma, relacionava o Teatro com o Ensino de Ciências Naturais e/ou Matemática, também não foi o último. Depois da defesa já escrevi várias peças teatrais na perspectiva do teatro didático, já produzi na escola algumas performances matemáticas, inclusive participei de alguns congressos (em apresentações culturais e com artigos publicados como relato de experiência). (F2).

Eu o utilizo todos os anos, porém não realizei nenhuma atualização ainda. O produto é muito bem aceito pelos alunos, facilitando o aprendizado. Hoje em dia precisamos envolver nossos alunos nos meios virtuais para que haja um maior interesse pelas disciplinas. $\left(Q_{3}\right)$

Um produto que promoveu a disseminação dos demais produtos educacionais elaborados pelo PPGECN/UFMT foi apresentado na pesquisa de Daron (2015), que relata o desenvolvimento e a aplicação de um aplicativo para celulares que funciona como uma ferramenta de organização e de acesso facilitado aos produtos educacionais elaborados pelo PPGECN/UFMT. Este aplicativo, em sua primeira versão, disponibilizou vinte e quatro produtos educacionais, todos eles, encontrados no sítio do programa (http://fisica.ufmt.br/pgecn/) no período de junho de 2012 a maio de 2015. Uma vez instalado no celular, o aplicativo funciona off-line, promovendo o acesso ilimitado por qualquer pessoa, a qualquer tempo, aos produtos educacionais. Nesta edição, a pesquisadora e egressa do curso, encontrou um acervo em formatos variados, prevalecendo arquivos em pdf, com uma propensão ao desenvolvimento de produtos na linha tecnológica, utilização de recursos audiovisuais, desenvolvimento de softwares, páginas html e Ambiente Virtual de Aprendizagem (AVA). Sua validação ocorreu a partir da utilização por professores da rede pública de ensino durante uma formação na sala do educador ${ }^{5}$. Esse é o tipo de produto educacional que pode/deve passar por aplicações e atualizações frequentes que o aperfeiçoe e que o mantenha na seara da inovação. 
A possibilidade de produção foi ampliada no último ano com a indicação de meios e formas de valorização dos materiais educacionais. A ênfase precisa ser entendida a partir da demanda pela sociedade. $\mathrm{O}$ produto precisa apresentar relação com as atividades do PIBID, PIBIC e com extensão. Precisam ser atrelados à ação docente de professores da educação e superior e ter um acesso facilitado por plataformas como a EduCAPES e o Portal de Periódicos para além daqueles já fornecidos pelos próprios programas.

O Qualis Educacional, agora será vigente tanto para os mestrados profissionais como para os acadêmicos. O que suscitará uma maior diversificação das produções e consequentemente, a compreensão mais bem fundamentada dessa produção acadêmica, que outrora era pouco aceita no âmbito dos MA.

As opções indicadas revelam o grande leque de possibilidades que vão, desde as mídias educacionais, como vídeos, simulações, animações, vídeo-aulas, experimentos virtuais, áudios, objetos de aprendizagem, aplicativos de modelagem, aplicativos de aquisição e análise de dados, ambientes de aprendizagem, páginas de internet e blogs, jogos educacionais, até protótipos educacionais e materiais para atividades experimentais. São bem-vindas, propostas de ensino (sugestões de experimentos e outras atividades práticas, sequências didáticas, propostas de intervenção, roteiros de oficinas, etc.); Material textual (manuais, guias, textos de apoio, artigos em revistas técnicas ou de divulgação, livros didáticos e paradidáticos, histórias em quadrinhos e similares); Atividades de extensão (exposições científicas, cursos, oficinas, ciclos de palestras, exposições, atividades de divulgação científica e outras); Materiais interativos (jogos, kits e similares). Até Desenvolvimento de softwares e aplicativos. Uma lista que não tem um limite definido e que conta com a criatividade do trabalho docente.

Atualmente, no sitio do PPGECN, estão disponíveis guias didáticos que tratam, por exemplo, de sequências didáticas (MARTINS, 2017), kits experimentais (VALENTIN, 2017), atividades práticas (RUVER, 2016), aplicativos (STEINERT, 2017), HQ (SANTOS, 2017), hipermídia (CARDOSO, 2013), para citar apenas alguns.

Neste novo quadriênio, a coordenação está propondo a revisão e a edição de todos os materiais educacionais já produzidos. A indicação é para que se proceda a adequação dos textos de apresentação, a inserção de uma ficha catalográfica; que se realize o registro ISBN, na plataforma EduCAPES para além de sua inclusão no sitio de programa, bem como a padronização de layouts como forma de melhorar a visualização desses produtos.

Aplicar o produto, apresentá-lo em eventos educacionais locais, regionais e nacionais e consequentemente, aprimorá-lo é a expectativa que alimentamos enquanto orientadores do programa. O que nem sempre é possível, tendo em vista as condições reais de atuação profissional. 
Entendemos que a visibilidade dos produtos educacionais é importante, seja nas plataformas de acesso, seja na apresentação em eventos. No entanto, é oneroso, tanto para o corpo docente quanto para o discente do programa, arcar com as despesas de registro, de edição e de apresentação desses materiais, uma vez que os programas de mestrados profissionais não são financiados.

Outra questão pertinente é o quanto estes produtos educacionais são respostas efetivas aos problemas de pesquisa propostos e, o quanto, estão realmente vinculados à prática docente. Nesta toada, Vital e Guerra (2017), em trabalho apresentado no XI ENPEC, apresentam análises dos discursos contidos nas dissertações e entrevistas de quatro egressos do MP que se dispuseram a utilizar a História da Ciência para ensinar conteúdos de Física a estudantes do Ensino Médio e que, estes egressos, ao atentarem para problemas da realidade escolar e buscarem soluções consultando diferentes fontes e recursos, acabaram adaptando suas práticas a partir de demandas criadas em distintas realidades escolares. Algumas dessas adaptações, segundo as autoras, representam recuos diante de restrições institucionais, apontando para um distanciamento entre a pesquisa e a prática docente. Concluem ainda que:

As adaptações feitas pelos docentes em suas práticas consistiram em alterações feitas nos momentos de reaplicação dos produtos educacionais em resposta às demandas criadas por discursos emanados da realidade escolar. Por outro lado, algumas dessas adaptações representaram recuos diante de discursos de autoridade que impuseram restrições institucionais, apontando para um distanciamento entre a pesquisa e a prática docente. Vital e Guerra (2017, p.8).

A pesquisa empreendida em um mestrado profissional, que estabelece a constituição de um produto educacional, considerando a variante do perfil desse ingressante, como alguém plenamente engendrado na prática profissional, não apenas sugere, mas confirma a expectativa de uma maior articulação entre a formação docente em continuidade, através do MP, bem como o recoloca diante da própria prática.

\section{CONCLUSÕES}

Como fora destacado, esta pesquisa tem um viés longitudinal e irá subsidiar a coordenação nas implementações necessárias à melhoria do curso no decorrer do quadriênio 2017-2020. Ou seja, mesmo que haja troca de coordenação neste período, objetiva-se a continuidade da pesquisa com posterior aprofundamento das análises.

É notório preliminarmente, que a construção dos produtos educacionais tem modificado a visão de planejamento e ação docente do egresso do PPGECN/UFMT. Sua aplicação no âmbito da escola tem sido quase imediata e seu impacto pode ser sentido na mudança de atitudes relacionadas à profissionalidade docente. Destaca-se, por exemplo, que 
o egresso se envolve mais com a gestão escolar, demonstrando boa capacidade de inserção. Em geral, eles vêm participando mais ativamente de decisões políticas da escola e da secretaria de educação do Estado. Procuram - e encontram - vagas no ensino superior, tanto na rede pública, quanto na privada e demonstram interesse em atualizar seu produto junto ao PPGECN a fim de disponibilizar uma nova versão que poderá ser acessada por internautas através do sítio do programa. A maioria deles mantém seus currículos lattes atualizados e podem ser encontrados nos eventos educacionais da UFMT.

Além disso, os egressos estão buscando dar continuidade à formação seguindo para o doutorado. Se a prerrogativa inicial era a de que, estes professores "se contentariam" com o título de mestre, os dados mostram que essa hipótese não é verdadeira.

Ainda que os egressos estejam mais bem engajados na atuação docente do que antes - perceptível pelo amplo envolvimento que estão tendo, não apenas na docência, mas também na gestão escolar, no CEFAPRO etc. - a formação em nível de mestrado tem lhes trazido a abertura intelectual para a pesquisa, seja da própria prática, seja de fundamentos teóricos e epistemológicos do ensino, bem como para a continuidade dos estudos em campos de interesses diversos.

Em resumo, esta pesquisa vem apontando para a necessidade de se fomentar um mestrado mais dinâmico e flexível, com momentos específicos de compartilhamento e trocas entre ingressantes e egressos, das dificuldades encontradas durante as etapas de constituição da pesquisa até sua finalização, bem como das possibilidades de atualização do produto educacional. Este último, precisa avançar para a inclusão nas plataformas de acesso facilitado e para a harmonização da apresentação em termos virtuais.

Um MP tem, como condição sine qua non, o desenvolvimento de um produto educacional como centro da dissertação. Entende-se que não é possível concretiza-lo sem uma ressignificação da epistemologia de partida do ingressante. Por isso, o programa vem primando pela discussão teórica e ao mesmo tempo pragmática e propositiva da natureza da ciência e de seus conceitos centrais. Entendemos, dessa forma, que os produtos educacionais se configurarão como aportes substanciais na prática docente de forma subsequente à sua defesa. E este, precisa ser revisitado, editado, modificado e seguir evoluindo conforme as necessidades formativas do egresso forem se apresentando.

Em consonância a CACHAPUz et al. (2005), compreendemos a importância da profundização epistemológica no desenvolvimento do mestrado. Uma meta a ser perseguida em cada uma das disciplinas e em cada uma das ações que compõem o currículo do programa.

Seguimos acreditando na melhoria da educação, não sem acreditar também que é preciso resignificar a profissão docente, em todos os âmbitos, sejam acadêmicos ou políticos, concebendo outro modo de valorização e participação desse profissional na constituição de uma educação mais próxima da ideal. 


\section{REFERÊNCIAS}

CACHAPUZ, Antônio. GIL-PEREZ, Daniel. PESSOA

DE CARVALHO, Anna Maria. PRAIA, João.

VILCHES, Amparo (orgs.). A necessária renovação

do ensino das ciências, São Paulo: Cortez, 2005.

CARDOSO, Mônica Santana. Hipermídia Termoquim: uma estratégia pedagógica para o ensino de química. 2013, 129 f. Dissertação (Mestrado Profissional em Ensino de Ciências Naturais) - Instituto de Física, Universidade Federal de Mato Grosso, 2013.

DARON, Érika Cassia de A. S. Kurpel. Espia lá: um aplicativo educacional em dispositivo móvel que organiza e facilita o acesso a produtos educacionais. 2015, 96 f. Dissertação (Mestrado Profissional em Ensino de Ciências Naturais) Instituto de Física, Universidade Federal de Mato Grosso, 2015.

FISCHER, Tânia. Mestrado profissional como prática acadêmica, RBPG, v. 2, n. 4, p. 24-29, jul. 2005.

LAGE, Maria Aparecida Guerra; URZETTA, Fabiana Cardoso; CUNHA, Ana Maria de Oliveira. Formação continuada de professores: entre os limites e os silêncios dos programas de formação. In: ENCONTRO NACIONAL DE PESQUISA EM EDUCAÇÃO EM CIÊNCIAS, 8, 2011, Campinas. Anais... Campinas: ABRAPEC, 2011.

MARTINS, Ana Laura da Silva. Uma proposta de sequência didática para o ensino de eletrólise na educação básica. 2017, 6of. Dissertação (Mestrado Profissional em Ensino de Ciências Naturais) - Instituto de Física, Universidade Federal de Mato Grosso, 2017.

NEPOMUCENO, Lívia Dias de Oliveira; COSTA, Helder Gomes. Mapeamento de Percepções na Avaliação dos Impactos do Mestrado Profissional no Perfil do seu Egresso. Production. v. 22, n. 4, p. 865-873, 2012.

OSTERMANN, Fernanda; REZENDE, Flavia. Projetos de Desenvolvimento e de Pesquisa na Área de Ensino de Ciências e Matemática: uma reflexão sobre os Mestrados Profissionais. Caderno Brasileiro de Ensino de Física. v. 26, n. 1, p. 66-80, 2009.

REZENDE, Flavia; OSTERMANN, Fernanda. O Protagonismo Controverso dos Mestrados Profissionais em Ensino de Ciências. Ciência \& Educação. v. 21, n. 3, p. 543-558, 2015. 
RUVER, Vilson Valdemar. A. Contribuição das Atividades Práticas nos Ensinos de Física e de Matemática. 2016, 66 f. Dissertação (Mestrado Profissional em Ensino de Ciências Naturais) - Instituto de Física, Universidade Federal de Mato Grosso, 2016.

SANTOS, Ricardo Figueiredo. A história da ciência viabilizando a contextualização no ensino de Física. 2017, 104 f. (Mestrado Profissional em Ensino de Ciências Naturais) Instituto de Física, Universidade Federal de Mato Grosso, 2017.

SCHÄFER, Eliane Dias Alvarez; OSTERMANN, Fernanda. Autonomia Profissional na Formação de Professores: uma análise de entrevistas realizadas num mestrado profissional em ensino de Física. Revista Electrónica de Enseñanza de las Ciencias. v. 12, n. 2, p. 287-312, 2013.

SILVEIRA, Vladmir Oliveira da. PINTO, Felipe Chaiarello de Souza. Reflexões necessárias sobre o mestrado profissional, RBPG, v. 2, n. 4, p. 38-47, jul. 2005.

STEINERT, Monica Erika Pardin. Sala de Aula, Um Sistema Autopoiético Para a Educação em Saúde Com Uso do Aplicativo SAMBI. 2017, 145 f. Dissertação (Mestrado Profissional em Ensino de Ciências Naturais) - Instituto de Física, Universidade Federal de Mato Grosso, 2017.

SOARES, Elane Chaveiro. A Pesquisa no ensino de Química nos programas de pós-graduação da UFMT: um panorama, In: XVIII Encontro Nacional de Ensino de Química (XVIII ENEQ), 2016, Florianópolis, SC, Brasil - 25 a 28 de julho de 2016. Anais, Disponível em: http://www.eneq2016.ufsc. br/anais/resumos/Ro112-1.pdf. Acesso em: 01 nov. 2017.

VALENTIM, João Augusto. Extração de Óleos Essenciais por Arraste a Vapor: Sequência Didática para Proporcionar Aprendizagem de Conceitos de Química. 2017, 108 F. Dissertação (Mestrado Profissional em Ensino de Ciências Naturais) - Instituto de Física, Universidade Federal de Mato Grosso, 2017.

VITAL, Abigail, GUERRA, Andreia. Produtos educacionais elaborados no Mestrado Profissional em Ensino: uma reflexão sobre a distância entre a pesquisa e a prática docente. In: Anais do XI Encontro Nacional de Pesquisa em Educação em Ciências - XI ENPEC Universidade Federal de Santa Catarina, Florianópolis, SC -3 a 6 de julho de 2017. 